\title{
PREVALENCE OF SUPERNUMERARY TEETH IN NORTH INDIAN POPULATION: A RADIOLOGICAL STUDY
}

\author{
Archana Rani ${ }^{* 1}$, Arvind Kumar Pankaj ${ }^{1}$, Rakesh Kumar Diwan ${ }^{1}$, Rakesh Kumar \\ Verma ${ }^{1}$, Anita Rani ${ }^{1}$, Jai Prakash Gupta ${ }^{2}$. \\ ${ }^{* 1}$ Department of Anatomy, King George's Medical University, Lucknow, Uttar Pradesh, India. \\ ${ }^{2}$ Provincial Medical Health Services UP, Faizabad, Uttar Pradesh, India.
}

\section{ABSTRACT}

Introduction: Supernumerary teeth are defined as any teeth or tooth substance in excess of the usual configuration of 20 deciduous and 32 permanent teeth. The reported prevalence of supernumerary teeth in the permanent dentition ranges from $0.1 \%$ to $3.8 \%$ and $0.3 \%$ to $0.6 \%$ in the deciduous dentition. The aim of the present study was to evaluate the prevalence of supernumerary teeth in the subjects attending the out-patient dental department of our setup, as the reports of this entity in North Indian population are rarely found in the literature.

Materials and Methods: Orthopentograms (OPGs) of 1025 subjects were collected from the Department of Oral Medicine \& Radiology, King George's Medical University, Lucknow. OPGs of permanent dentition were only considered for the study. OPGs were studied carefully for various types of supernumerary teeth and prevalence was calculated.

Results: The prevalence of supernumerary teeth was calculated according to their location. They were observed in only $0.8 \%$ cases. The prevalence of mesiodens was $0.2 \%$, paramolar $0.1 \%$, distomolar $0.4 \%$ and parapremolar was noticed in $0.1 \%$ case. Considering the morphological classification, only conical variety was seen in $0.2 \%$ cases. Males (62.5\%) were found to be more commonly affected than females (37.5\%).

Conclusion: The prevalence of supernumerary teeth was $0.8 \%$ in present study of which distomolar was the most common variety. The unique finding was that the females were having tendency for distomolar type only. Supernumerary teeth may erupt or remain impacted and may lead to various complications. Findings of the present study may be useful for clinicians for proper diagnosis and management of supernumerary teeth.

KEY WORDS: Dentition, Distomolar, Mesiodens, Orthopentogram.

Address for Correspondence: Dr. Archana Rani, MD, Professor, Department of Anatomy, King George's Medical University, Lucknow- 226003, Uttar Pradesh, India. Contact no.: +919451950799

E-Mail: archana71gupta@yahoo.co.in

\section{Access this Article online}

\section{Quick Response code}

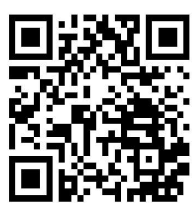

DOI: $10.16965 /$ ijar.2017.204

Web site: International Journal of Anatomy and Research ISSN 2321-4287

www.ijmhr.org/ijar.htm

Received: 28 Mar 2017

Peer Review: 28 Mar 2017

Revised: None
Accepted: 08 May 2017

Published (O): 31 May 2017

Published (P): 31 May 2017

\section{INTRODUCTION}

Supernumerary teeth are defined as any tooth or odontogenic structure that is formed from a tooth germ in excess of the usual number for any given region of the dental arch [1]. Supernumerary teeth have been found in all areas of the dental arches and may present in both the permanent and primary dentitions, but are five times less frequent in the primary dentition [2]. Supernumerary teeth appear with a higher frequency in men than in women, with a 2:1 ratio $[3,4]$. The reported frequency in permanent dentition varies from 0.1 to $3.6 \%$ in the general population [5]. A few cases of inherited forms have also been reported [2].

Supernumerary teeth (ST) have been classified 
mainly based on their morphology and location. According to the morphology as conical, tuberculate, supplemental, and odontoma $[4,6]$. Mitchell (1989) classified ST on basis of location as mesiodens, paramolar, and distomolar [4]. While Scheiner and Sampson (1997) classified it as mesiodens, paramolar, distomolar, and parapremolars [6]. The mesiodens is located between the two central incisors and these are mostly conical in shape [7]. Distomolars are located distally to the third molar, while paramolars are located palatally or labially next to a molar [8]. Parapremolars are located adjacent to a premolar.

ST occur singly or in multiples, unilaterally or bilaterally, either in maxilla, mandible, or both [3]. They occur ten times more in maxilla, especially premaxilla, than mandible $[5,9]$. Multiple supernumerary teeth may be associated with conditions such as cleidocranial dysplasia, Gardner syndrome, and cleft lip and cleft palate. Clinically, it can cause disorders like retention of primary teeth, delayed eruption of permanent teeth, ectopic eruptions, tooth displacements, follicular cysts, and other alterations which require surgical as well as orthodontic treatments [10].

They are more commonly located on the maxillary midline, where they are referred to as mesiodens, representing $80 \%$ of all the supernumerary teeth. This location is followed in decreasing order of frequency by upper distomolars, upper paramolars and proportionately far behind by lower premolars, upper lateral incisors, lower distomolars and lower central incisors. Upper premolars are exceptional, as are upper and lower canines and lower lateral incisors [11].

\section{MATERIALS AND METHODS}

Digital Panoramic Orthopentograms (OPGs) of 1025 subjects attending the Department of Oral Medicine \& Radiology, King George's Medical University, Lucknow were collected in a CD (soft copy) for retrospective study of supernumerary teeth. OPGs of permanent dentition were only considered for the study. OPGs of children and persons with fallen teeth were not included in the study. OPGs were studied carefully on a computer by a skilled dentist for various types of supernumerary teeth according to location and morphology to analyse their prevalence in North Indian population. Gender wise prevalence was also documented.

\section{OBSERVATIONS AND RESULTS}

Among radiographs of 1025 patients, the prevalence of ST according to location was observed in only $0.8 \%$ cases $(n=8)$ of which $0.7 \%(n=7)$ were located in maxilla (upper arch) and $0.1 \%$ $(n=1)$ in mandible (lower arch). Mesiodens was observed in $0.2 \%$ cases $(n=2)$ in maxillary arch of which one case depicted one mesiodens (Fig. 1a) while the other case showed two mesiodens (Fig.1b). Paramolar was witnessed in $0.1 \%$ case $(n=1)$ which was bilateral, present between first and second molar on both sides and mandibular in origin (Fig. 2). Prevalence of distomolar was $0.4 \%(n=4)$ of which three cases exhibited left distomolar (Fig. 3a) and one case revealed bilateral distomolar (Fig. 3b), all were maxillary in origin. Parapremolar was viewed in $0.1 \%$ case $(n=1)$ which was maxillary and situated on left side (Fig. 4). Considering the morphological classification, only conical variety was seen in $0.2 \%$ cases $(n=2)$ which was mesiodens in location wise (Fig. 1a\&b). Tuberculate, supplemental and odontome variety were not seen in the present study. Higher prevalence of ST was noticed in males $(n=5,62.5 \%)$ as compared to females $(n=3$, $37.5 \%)$. Mesiodens $(n=2)$, paramolar $(n=1)$ and parapremolar $(n=1)$ were only seen in males. Distomolars $(n=4)$ were present in both genders but higher predilection in females ( 1 male and 3 females).

Fig. 1a: OPG showing one mesiodens (arrow) in maxillary arch.

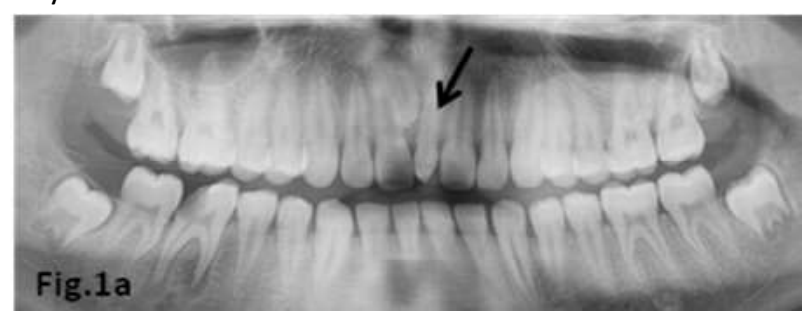

Fig. 1b: OPG showing two mesiodens (arrows) in maxillary arch.

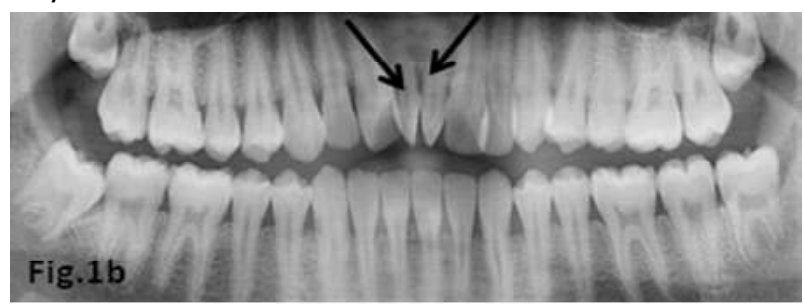


Fig. 2: OPG showing bilateral paramolar (arrows) in mandibular arch.

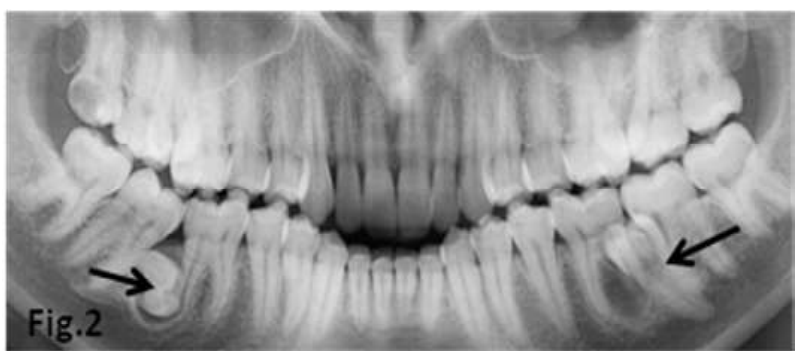

Fig. 3a: OPG showing left distomolar (arrow) in maxillary arch.

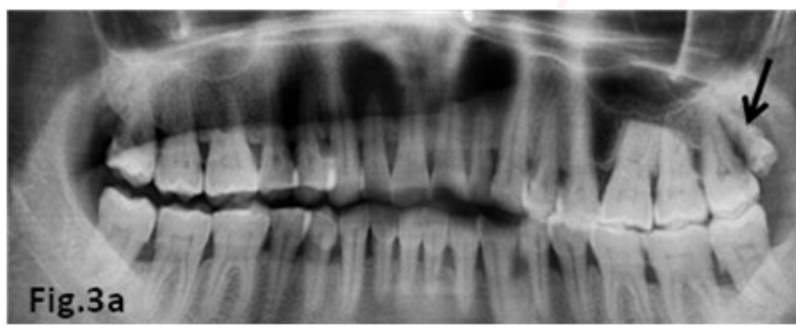

Fig. 3b: OPG showing bilateral distomolar (arrows) in maxillary arch.

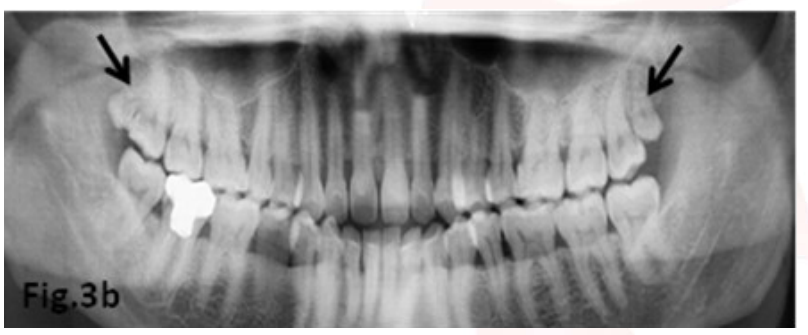

Fig. 4: OPG showing left parapremolar (arrow) in maxillary arch.

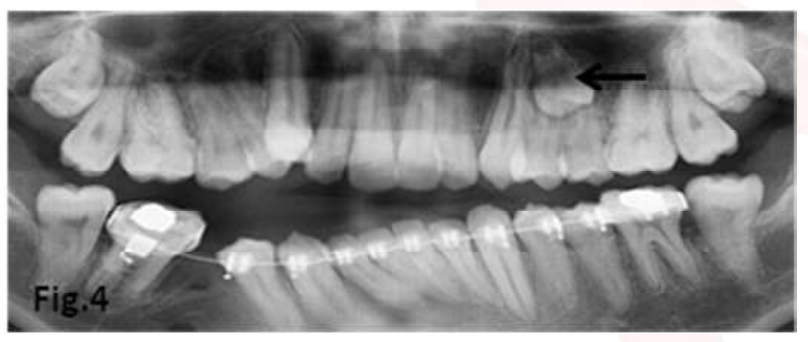

\section{DISCUSSION}

Supernumerary teeth are not an uncommon finding in dental practice, occurring in $0.1-3.8 \%$ of the population [12-14]. Several studies have been done to know the incidence of the supernumerary teeth in different populations.

The prevalence of supernumerary teeth in the present study was $0.8 \%$ which is in agreement with the previous studies. Mahabob et al. (2012) examined 2216 non-syndromic South Indian population and found that out of total 27 supernumerary teeth, $18(66.7 \%)$ were located in the maxilla and 9 (33.3\%) in the mandible. In maxilla, the most common supernumerary teeth was mesiodens $(44.44 \%, n=12)$ followed by distomolar (14.81\%, $\mathrm{n}=4)$ and premolar $(7.4 \%$, $\mathrm{n}=2$ ) while in mandible, the most common location was premolar $(22.22 \%, n=6)$ followed by distomolar (11.11\%, n=3) [15]. Saha et al. (2016) also noted similar findings in Bengali population of India. He witnessed that in 89 cases $(70.1 \%)$, ST were present in the upper arch; in 28 cases $(22.0 \%)$ in the lower arch and in 10 cases $(7.9 \%)$ they were present in both the arches [16].

The findings of our study runs parallel with these studies, as we also found that the maximum number of supernumerary teeth was located in maxilla $(0.7 \%, n=7)$ as compared to mandible $(0.1 \%, n=1)$. Gopakumar et al. (2014) found that the maximum incidence of supernumerary teeth in South Kerala region (South India) was mesiodens $(0.14 \%)$ followed by paramolars $(0.13 \%)$, third premolar $(0.04 \%)$ and distomolar $(0.03 \%)[17]$. But the present study in North Indians reported that the most common supernumerary teeth was distomolar $(0.4 \%, n=4)$ followed by mesiodens $(0.2 \%, n=2)$, paramolar $(0.1 \%, n=1)$ and parapremolar $(0.1 \%, n=1)$. Schmuckli et al. (2010) studied the supernumerary teeth in Swiss community and noted that the conical variety was the most frequent type, comprising $70 \%$, followed by the supplemental $(25 \%)$ and the tuberculate (5\%) morphological types [18]. We noted only the conical type (0.2\%), rest of them was not seen in our study.

Fardi et al. (2011) done a radiographic study in a North Greek population and reported the prevalence of supernumerary teeth to be $1.8 \%$ [19]. Bäckman and Wahlin (2001) clinically examined 739 Caucasian children and found 14 cases with at least one supernumerary tooth. They also noted that the majority of the supernumerary teeth were mesiodens [12]. Results of a study investigating the frequency of supernumerary teeth in a Mexican population suggested that mesiodens was the most frequent, followed by premolars, lateral incisors and 4th molars [20]. In a survey of 2,000 school children, Brook (1974) found that supernumerary teeth were present in $0.8 \%$ of primary dentitions and in $2.1 \%$ of permanent dentitions [21].

In permanent dentition, the prevalence ranges from $0.4 \%$ to $2.1 \%$ for Caucasians while $2.4 \%$, $3.4 \%$, and $6 \%$ for Southern Chinese [22], Japanese [23], and American Blacks [24]. 
Van der Merwe and Steyn (2009) reported a higher incidence of ST (7\%) in a South African mining community of the skeletal remains [25]. Gender wise distribution of our study runs parallel with the findings of Brook (1974) who also reported that the incidence of ST for males was higher than females [21]. Contrarily, Bäckman and Wahlin (2001) reported more female predilection [12]. Mitchell (1989) reported that females are more commonly affected than males with a 2:1 ratio in permanent, while no significant difference was found in primary dentition [4]. But the unique finding of our study is that distomolars are more common in females as compared to males in North Indian population which was not reported in the literature till now.

The results of the present study are comparable to the data reported in other studies, while the dissimilarities may be attributed to the sample selection, method of the study, assessment process, racial and genetic differences in different population.

Anomalies of teeth may be due to defects caused by genetic disturbances or environmental factors during tooth morphogenesis. The favoured hypothesis is the excessive growth of the dental lamina or hyperactivity of the dental lamina, which can be proposed as being responsible for the formation of additional tooth germs [26]. According to this theory, the lingual extension of an additional tooth bud leads to a eumorphic tooth, while the rudimentary form arises from proliferation of epithelial remnants of the dental lamina induced by the pressure of the complete dentition [27]. However, combinations of genetic and environmental factors were shown to be responsible factors for the occurrence of ST.

ST may erupt or remain unerupted. Due to their shape and volume they often hinder eruption and development of the permanent tooth related to them, causing crowding, displacement, diastema, retention, radicular resorption [28]. If the supernumerary teeth are related to local disorders (diastema, delayed eruption or displacement) or if there is associated pathology, they should be extracted whenever the problem would be detected [29].

\section{CONCLUSION}

The prevalence of supernumerary teeth was $0.8 \%$ in present study with higher predilection in males than females. Various complications can occur if supernumerary teeth remain impacted. Therefore, clinically as well as radiologically, a sound knowledge is necessary for better patient care.

\section{Conflicts of Interests: None}

\section{REFERENCES}

[1]. Shafer WG, Hine MK, Levy BM. A textbook of oral pathology. $4^{\text {th }}$ Edition. Philadelphia: W.B. Saunders, 1983.

[2]. Burzynski NJ, Escobar VH. Classification and genetics of numeric anomalies of dentition. Birth Defects Orig Artic Ser. 1983;19:95-106.

[3]. Rajab LD, Hamdan MA. Supernumerary teeth: review of the literature and a survey of 152 cases. Int J Paediatr Dent. 2002;12:244-54.

[4]. Mitchell L. Supernumerary teeth. Dent Update. 1989;16(2):65-69.

[5]. Acikgoz A, Acikgoz G, Tunga U, Otan F. Characteristic and prevalence of non-syndrome multiple supernumerary teeth: A retrospective study. Dentomaxillofac Radiol. 2006;35:185-90.

[6]. Scheiner MA, Sampson WJ. Supernumerary teeth: a review of the literature and four case reports. Aust Dent J. 1997;42:160-5.

[7]. Bolk L. The supernumerary upper incisors of man. Deutsch Mschr Zahnheilk. 1917;35:185-228.

[8]. Bolk L. Supernumerary teeth in molar region in man. Dental Cosmos. 1914;56:154-167.

[9]. Yusof WZ. Non-syndrome multiple supernumerary teeth: Literature review. J Can Dent Assoc. 1990;56:147-9.

[10]. Zilberman Y, Malron M, Shteyer A. Assessment of 100 children in Jerusalem with supernumerary teeth in the premaxillary region. ASDC J Dent Child. 1992;59:44-7.

[11]. Danalli DN, Buzzato JF, Braum TW, Murphy SM. Longterm interdisciplinary management of multiple mesiodens and delayed eruption: report of a case. J Dent Child. 1988;55:376-80.

[12]. Bäckman B, Wahlin YB. Variations in number and morphology of permanent teeth in 7-year-old Swedish children. Int J Paediatr Dent. 2001;11(1):11-7.

[13]. Salem G. Prevalence of selected dental anomalies in Saudi children from Gizan region. Community Dent Oral Epidemiol. 1989;17(3):162-3.

[14]. Luten JR Jr. The prevalence of supernumerary teeth in primary and mixed dentitions. J Dent Child. 1967;34(5):346-53.

[15]. Mahabob MN, Anbuselvan GJ, Kumar BS, Raja S, Kothari S. Prevalence rate of supernumerary teeth among non-syndromic South Indian population: An analysis. J Pharm Bioallied Sci. 2012;4 (Suppl 2):S373-5. 
[16]. Saha A, Das AK, Biswas S, Nair V, Das KP, Roy U. Prevalence of supernumerary teeth in bengali population of India. International Journal of Contemporary Medical Research. 2016;3(4):1005-1008.

[17]. Gopakumar D, Thomas J, Ranimol P, Vineet DA, Thomas S, Nair VV. Prevalence of supernumerary teeth in permanent dentition among patients attending a dental college in South Kerala: A pilot study. J Indian Acad Oral Med Radiol. 2014;26:42-5.

[18]. Schmuckli R, Lipowsky C, Peltomäki T. Prevalence and morphology of supernumerary teeth in the population of a Swiss community. Schweiz MonatsschrZahnmed. 2010;1201(1):987-93.

[19]. Fardi A, Kondylidou-Sidira A, Bachour Z, Parisis N, Tsirlis $A$. Incidence of impacted and supernumerary teeth-a radiographic study in a North Greek population. Med Oral Patol Oral Cir Bucal. 2011s;16(1):e56-61.

[20]. Salcido-García JF, Ledesma-Montes C, HernándezFlores F, Pérez D, Garcés-Ortíz M. Frequency of supernumerary teeth in Mexican population. Med Oral Patol Oral Cir Bucal. 2004;9:407-9.

[21]. Brook AH. Dental anomalies of number, form and size: their prevalence in British school children. J Int Assoc Dent Child. 1974;5:37-53.

[22]. Tsai SJJ, King NM. A catalogue of anomalies and traits of the permanent dentition of southern Chinese. J ClinPediatr Dent. 1998;22(3):185-94.
[23]. Niswander JD, Sujaku C. Congenital anomalies of teeth in Japanese children. Am J PhysAnthropol. 1963;2:569-74.

[24]. Harris EF, Clark LL. An epidemiological study of hyperdontia in American blacks and whites. Angle Orthod. 2008;78(3):460-5.

[25]. Van der Merwe AE, Steyn M. A report on the high incidence of supernumerary teeth in skeletal remains from a 19th century mining community from Kimberley, South Africa. SADJ. 2009;64(4):162-66.

[26]. Dhull KS, Acharya S, Ray P, Yadav S, Prabhakaran SD. Bilateral maxillary paramolars: a case report. J Dent Child (Chic). 2012;79(2):84-7.

[27]. Richardson A, Deussen FF. Facial and dental anomalies in cleidocranial dysplasia: A study of 17 cases. Int J Paediatr Dent. 1994;4(4):225-31.

[28]. Ferrés-Padró E, Prats-Armengol J, Ferrés-Amat E. A descriptive study of 113 unerupted supernumerary teeth in 79 pediatric patients in Barcelona. Med Oral Patol Oral Cir Bucal. 2009;14(3):E146-52.

[29]. Liu DG, Zhang WL, Zhang ZY, Wu YT, Ma XC. Threedimensional evaluations of supernumerary teeth using cone-beam computed tomography for 487 cases. Oral Surg Oral Med Oral Pathol Oral Radiol Endod. 2007;103 (3):403-11. How to cite this article:
Archana Rani, Arvind Kumar Pankaj, Rakesh Kumar Diwan, Rakesh
Kumar Verma, Anita Rani, Jai Prakash Gupta. PREVALENCE OF SUPER-
NUMERARY TEETH IN NORTH INDIAN POPULATION: A RADIOLOGI-
CAL STUDY. Int J Anat Res 2017;5(2.2):3861-3865. DOI: 10.16965/
ijar.2017.204 